\title{
Recurrent spontaneous CSF rhinorrhea: combined endo-nasal endoscopic repair with lumbo-peritoneal shunt insertion
}

\author{
Ahmed Y. Soliman ${ }^{1 *}$, Kamal Ebeid ${ }^{2}$ and Amr Abu Elfadle ${ }^{3}$
}

\begin{abstract}
Background: Spontaneous cerebrospinal fluid (CSF) leaks are associated with high morbidity and recurrence rates. Most cases had increased intracranial pressure (ICP) on presentation. There is still controversy regarding the use of lumbo-peritoneal shunt to prevent its recurrence.

Aim: This study was conducted to evaluate the impact of lumbo-peritoneal CSF shunt following the initial as well as recurrent repair of spontaneous CSF leaks to avoid recurrence.

Methods: A retrospective cohort study reviewed patients with recurrent spontaneous CSF leaks over a 4-year period. All patients had increased ICP and were subjected to endoscopic repair and lumbo-peritoneal shunt procedure.
\end{abstract}

Results: Eighteen patients were included in this study. Most patients were obese (BMI $\left.=33.6 \pm 1.8 \mathrm{~kg} / \mathrm{m}^{2}\right)$ women (88.9\%), with sleep apnea syndrome (77.8\%). All patients presented with headache and visual complaints. Meningitis was recorded in two patients (11.1\%). The most common sites of leakage were the cribriform (66.7\%), followed by both cribriform and ethmoidal (16.7\%), sphenoid (11.1\%), and ethmoidal (5.6\%) bones. The mean defect size was $5.1 \pm 1.1 \mathrm{~mm}$. About one third of cases had multiple defects. Encephalocele and meningocele were encountered in $61.1 \%$ and $66.7 \%$ of cases, respectively. The mean preoperative CSF pressure was $36.5 \pm 1.7 \mathrm{~mm} \mathrm{H} \mathrm{H}_{2} \mathrm{O}$. Lumbo-peritoneal shunt was inserted for all our patients. The failure rate of repair was $11.1 \%$.

Conclusion: Success rate is higher in patients with spontaneous CSF leaks and CSF hypertension treated by lumbo-peritoneal shunt. Future prospective studies with larger sample sizes should confirm the efficacy and safety of this management plan.

Keywords: Endoscopy, Spontaneous, Cerebrospinal, Leak, Lumbo-peritoneal shunt

\section{Introduction}

The leakage of cerebrospinal fluid (CSF) may occur due to the development of defect(s) in the mucosa, skull bone, and meningeal membranes [1]. Defects in the skull base may occur congenitally, due to trauma, neoplasm, or spontaneously. The etiology of spontaneous CSF leaks has not yet been elucidated; however, it is associated with increased intracranial pressure (ICP) than the

\footnotetext{
* Correspondence: ahmad.soliman@med.tanta.edu.eg

${ }^{1}$ Faculty of Medicine, Tanta University, Tanta 31527, Egypt

Full list of author information is available at the end of the article
}

tensile strength of the disrupted tissues; thus, it is considered as a variant of idiopathic intracranial hypertension $(\mathrm{IIH})[2-6]$.

Life-threatening sequelae have been associated with CSF leaks, such as ascending meningitis or brain abscess. Repair of anterior cranial base CSF leaks is now mostly done endoscopically through the nose to decrease the morbidity associated with open approaches [7]. Unfortunately, the rate of recurrence after surgical repair in cases of spontaneous CSF leaks (25-87\%) is much higher 
than the rates $(<10 \%)$ reported after repair of CSF leaks with other etiologies $[8,9]$.

Active management of CSF hypertension seems a rational procedure in cases of spontaneous CSF leaks, particularly as elevated CSF pressure in the postoperative period in those patients was reported by several previous studies $[3,8,10]$. Control of increased CSF pressure can be achieved by either administration of acetazolamide or CSF diversion by lumbo-peritoneal shunt [11].

Lumbo-peritoneal shunting is an effective, and safe procedure that has been used to treat IIH. The efficacy of this kind of shunting is maintained as long as the shunt remains patent [12]. It has the advantages of short performance time and being suitable for patients with morbid obesity [13]. However, there is still conflicting reports and debate considering the efficacy of lumboperitoneal shunts in preventing failure of repair and recurrence of CSF leaks. Moreover, no previous studies, up to the best of the authors' knowledge, investigated recurrent spontaneous CSF rhinorrhea. Therefore, the current study aimed to evaluate the impact of lumboperitoneal shunting on success rate and prevention of recurrence in patients with elevated CSF pressure and spontaneous CSF leak.

\section{Methods}

\section{Settings and ethical considerations}

This retrospective cohort study was approved by the Institutional Review Boards and the Ethical Committees of our University. Confidentiality of the patients' data was considered by assigning code numbers to the patients (known only by the researchers) and safe keeping of all patients' information.

All patients with spontaneous CSF leaks who underwent previous repair surgeries during a 4-year period (from February 2015 to April 2019) at our institute were included in this study. Patients were excluded if the etiology of CSF leaks was identified as congenital, traumatic, or neoplastic.

We collected data of the history (previous head trauma, previous sinus or neurological surgery, or prior attacks of meningitis and obesity) and physical examination including nasal endoscopy and body mass index (BMI) calculation. B2 transferrin was the main laboratory investigation for confirmation of CSF nature.

All patients underwent radiographic imaging included combined thin slices $(1 \mathrm{~mm}) \mathrm{CT}$ scans and MRI 1.5-T MR scanner (Achieva and Ingenia, Philips medical system, Eindhoven, Netherlands) of the paranasal sinuses and skull base for detection of site and size of the defects, only one patient had been referred to our center with full investigations including CT cisternography, and this was not our routine in our center. In addition, operative notes and operative videos were reviewed and data regarding demographics, nature of presentation, surgical approach, reconstructive technique, management of ICP, clinical follow-up, and complications were collected.

All patients were operated upon by an otolaryngologist and two neurosurgeons for revision surgeries. The transnasal endoscopic approach was adopted in all cases according to the size and sites of the defects detected preoperatively. Transethmoidal exposure was the standard approach for cribriform plate, and ethmoidal roof defects with additional transpterygoid approach if lateral sphenoidal recess defects were encountered (Fig. 1).

Transethmoidal approach in such revision cases was somewhat difficult than primary surgery due to loss of some anatomical landmarks and scarring from primary surgery. So, we depended mainly on stable landmarks mainly medial orbital wall, middle meatus, and choana. Surgery was done under general anesthesia with a total intravenous anesthesia technique for optimization of operative field combined with local application of diluted adrenaline with saline $(1: 100000)$ by cotton pledgets for $10 \mathrm{~min}$. The patient's head was positioned at 45 degrees for decreasing head and neck congestion. A diagnostic nasal endoscopy was first done using a 4-mm rigid endoscope connected to a high-definition camera head. After that, a revision uncinectomy and middle meatal antrostomy were first done if it was not done in the primary surgery. Anterior and posterior ethmoidectomy and sphenoidotomy were then done and skull base cleared from posterior till the anterior ethmoid artery. The opening of the frontal sinus was identified and widened. The ostia of all sinuses were opened. At this stage, the attention was turned to the site of the leak, which was preoperatively determined by thin slices $1 \mathrm{~mm}$ plain $\mathrm{CT}, \mathrm{MRI}$, and intraoperatively delineation. In the presence of meningocele or meningoencephalocele, bipolar cauterization was sufficient till the shrinking of them. After the identification of the skull base defect, the mucosa all around it was denuded using curettes and bipolar cauterization for getting the maximum healing of grafts and flaps.

Small circular defects up to $5 \mathrm{~mm}$ were plugged with a single piece of fat which was harvested from anterior abdominal wall or lateral aspect of the thigh. In some cases, overlay mucoperichondrial grafts harvested from the nasal septum were placed over the fat plugs. Cases with defects larger than $5 \mathrm{~mm}$ combined underlay fascia lata graft between brain and dura matter with fat plugs through osseous defect was applied. Finally, the graft was then stabilized by layers of Surgicel and absorbable Gelatin.

In case of sphenoid CSF leaks, a transpterygoid approach was adopted. The sphenoid sinus ostium in the region of sphenoethmoidal recess $7-10 \mathrm{~mm}$ superior to 

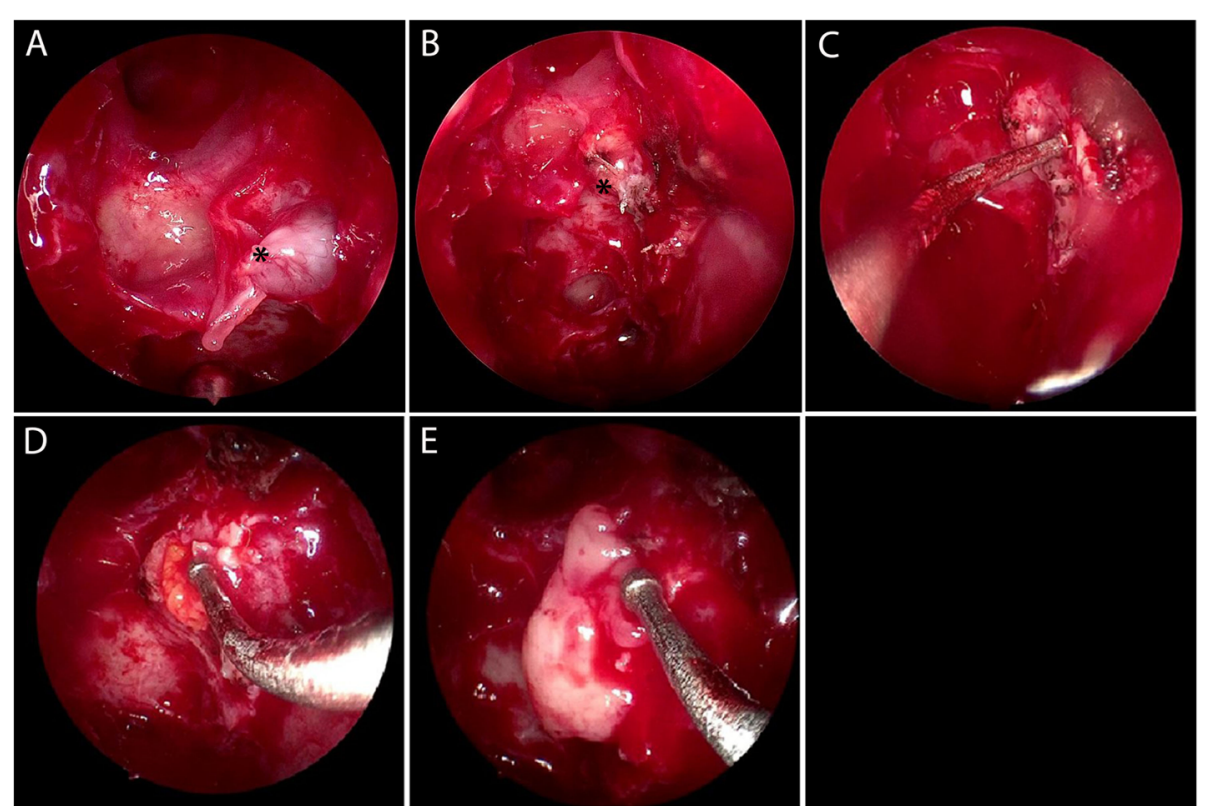

Fig. 1 Transnasal endoscopy showing: right side encephalocele $\left(^{*}\right)$ from cribriform plate after transethmoidal exposure using $45^{\circ}$ endoscope $($ a) the encephalocele $\left(^{*}\right)$ after bipolar cauterization $(\mathbf{b})$, refreshment of the edges using probe $(\mathbf{c})$, insertion of auricular fat graft through the defect (d), and application of nasal septal mucoperichondrial graft over the defect (e)

the choanal opening was identified. Drilling of the pterygoid body with a 4-mm coarse diamond drill till the lateral sphenoid recess was achieved. To avoid the injury of vidian and maxillary nerves, a 4-mm 45 degrees endoscope (Karl Storz ${ }^{\circ}$, Tuttlingen, Germany) was crucial at this stage. After the defect identification, the meningocele was cauterized and all-around mucosa was denuded using curettes and curved bipolar cauterization. Lateral recess of sphenoid was reconstructed using multilayer technique which included plugging with fat grafts then covering with fascia lata and all covered with vascularized nasoseptal flap, which was previously designed at the initial stages of operation based on the posterior septal artery. Then, stabilization by layers of Surgicel (Ethicon Ltd., UK) and absorbable gelatin was applied.

Non-absorbable packing was placed in all cases and removed 4 to 5 days postoperatively.

All cases received anti-staphylococcal antibiotics, and all cases have been instructed to avoid straining and heavy work for 6 weeks.

Pre-operative open pressure CSF manometry through lumbar puncture for all cases was done in between active attacks of leaks and after achievement of endoscopic skull base defects' repair, Lumbo-peritoneal shunt has been inserted at the same surgical setting for cases with open pressure more than $30 \mathrm{~mm} \mathrm{H}_{2} \mathrm{O}$ using (Medtronic 44430 NSC Lumboperitoneal Shunt Kit (X) (USA Made).

Patients were repositioned from supine after achievement of endoscopic repair into a lateral decubitus position between either L3-4 or L4-5 fluoroscopic-guided epidural Touhy needle was introduced into the thecal sac with its bevel up allowing CSF release and open pressure measurement at that point.

The proximal end of lumboperitoneal catheter was introduced through Touhy needle (Tuohy Needle, 14 Gauge, 3.5" w Huber Tip- Medtronic 44430 NSC USA Made ) till reaching 7-9 cm intrathecally to allow some displacement of the needle out from the thecal sac, and the catheter was sutured into the lumbar fascia with 4-0 silk suture into the anchoring device of the catheter to avoid its displacement from the thecal sac, then the distal end was tunneled subcutaneously after examination of CSF drippling. The peritoneal cavity was surgically approached, and the distal end of the catheter was inserted through it with about $20-25 \mathrm{~cm}$, then fixed with purse-string sutures to guard against displacement. Closure was achieved in a standard fashion.

Patients were discharged after 1 week following surgery, and they were advised for follow-up after 2 weeks, 1 month, 3 months, and once every 3 months. Outpatient diagnostic nasal endoscopy was done at the end of the fourth week to assess the nasal cavity for graft take up. CT scan post-operatively was advised at the end of 6 months.

Statistical analysis was performed using the Statistical Package for Social Sciences (IBM SPSS Statistics) for Windows, version 26 (IBM Corp., Armonk, N.Y., USA). For quantitative data, the Shapiro-Wilk test for normality was performed. For data that followed normal distribution, values were expressed as mean \pm standard 
deviation. For data that did not follow normal distribution, median and interquartile ranges (expressed as 2575 percentiles) were calculated. For qualitative data, the variables were summarized as frequencies (count and percentage).

\section{Results}

Eighteen patients were included in the present study, the demographic characteristics of the studied patients. Their age ranged from 22 to 42 years old, with a mean age of $33.3 \pm 5.9$ years old. The majority of patients were women (88.9\% versus $11.1 \%)$. The BMI ranged from 30 to $36 \mathrm{~kg} / \mathrm{m}^{2}$, with an average of $33.6 \pm 1.8 \mathrm{~kg} / \mathrm{m}^{2}$. Obstructive sleep apnea (OSA) syndrome was recorded in $77.8 \%$ of case (Table 1 ).

As regard clinical manifestations and radiological findings in the studied patients, the majority of patients (89.9\%) presented with unilateral clear watery nasal discharge increased with leaning forward as well as headache and visual complaints. Only two patients (11.1\%) suffered from meningitis at presentation. The most common site of leakage was the cribriform (66.7\%), followed by leakage from both cribriform and ethmoidal (16.7\%), then sphenoid (11.1\%), and only one case with leakage from ethmoidal (5.6\%) roof (fovea ethmoidalis). The defect size ranged from 3 to $7 \mathrm{~mm}$, with an average of 5.1 $\pm 1.1 \mathrm{~mm}$. The defect was single in most cases (66.7\%), with only $33.3 \%$ of cases having multiple defects most of later defects were actively leaked. Encephalocele and meningocele were encountered in $61.1 \%$ and $66.7 \%$ of cases, respectively. Examination with MRI revealed empty sella totalis in $66.7 \%$, slit ventricle in $27.8 \%$, empty sella partialis in $5.6 \%$ of patients, and CSF congestion around optic nerve sheath in $77.7 \%$ (Fig. 2).

Fundoscopy was done for all the patients and different grades of papilledema as well as post-papilledmic optic

Table 1 Demographic data

\begin{tabular}{ll}
\hline Parameter & Total number $\mathbf{= 1 8}$ \\
\hline Age (years) & \\
Mean \pm SD & $33.3 \pm 5.9$ \\
Range & $22.0-42.0$ \\
Gender & \\
Female & $16(88.9 \%)$ \\
Male & $2(11.1 \%)$ \\
BMI (kg/ $\left.\mathbf{m}^{2}\right)$ & \\
Mean \pm SD & $33.6 \pm 1.8$ \\
Range & $30.0-36.0$ \\
Sleep apnea syndrome & \\
No & $4(22.2 \%)$ \\
Yes & $14(77.8 \%)$ \\
\hline
\end{tabular}

$S D$ standard deviation, $B M I$ body mass index atrophy were recorded in $77.7 \%$ of which $55.55 \%$ were different grades of papilleodema which resolved during post-operative follow-up. Moreover, 22.22\% were postpapilledemic optic atrophy and stay as it in the postoperative follow-up fundoscopic examination.

Preoperative manometry of CSF pressure revealed a pressure ranging from 35 to $40 \mathrm{~mm} \mathrm{H}_{2} \mathrm{O}$, with an average of $36.5 \pm 1.7 \mathrm{~mm} \mathrm{H}_{2} \mathrm{O}$ (Table 2).

Most of the patients (88.9\%) had one previous repair, while $11.1 \%$ had previous two repairs. Repair was achieved using fat and mucopericondrium in $50 \%$ of cases, with fat only in $38.9 \%$, and with fat and fascia lata then covered with vascularized naso-septal flap in $11.1 \%$ of cases. The repair failed in only two cases $(11.1 \%)$ as a result of shunt obstruction. Patients were followed-up after repair for a period ranging from 6 to 60 months, with a median follow-up period of 24.5 months (Table 3 ).

\section{Discussion}

The present study included 18 patients with spontaneous CSF leaks. All of the patients were young adults, with a mean age of $33.3 \pm 5.9$ years old, which is slightly younger than reported by earlier studies (average age $45-65$ years) [14-16].

Female patients outnumbered male patients in the present study ( $88.9 \%$ versus $11.1 \%)$, with a ratio of approximately $8: 1$. The higher prevalence of spontaneous CSF leaks in women was also reported by other studies, with a female: male ratio ranging from approximately 2 : 1 to $7: 3[4,8,14,15,17]$.

All patients in our series were obese, with their BMI ranging from 30 to $36 \mathrm{~kg} / \mathrm{m}^{2}$, (mean $=33.6 \pm 1.8 \mathrm{~kg} / \mathrm{m}^{2}$ ). This finding is in agreement to other studies that showed an association between spontaneous CSF leaks with obesity, with an average BMI ranging from 32 to 38 $\mathrm{kg} / \mathrm{m}^{2}$ in such patients $[4,8,14-20]$. Previous studies have suggested that obesity is not a direct cause of spontaneous CSF leaks, but other conditions associated with obesity may contribute to the development of leaks, including IIH and OSA syndrome [14, 15, 21, 22].

In our series of patients, OSA syndrome was recorded in $77.8 \%$ of cases. This prevalence is analogous to that reported by a prospective study (83.3\%) which assessed patients having spontaneous CSF leaks with polysomnography [22]. However, much lower prevalence rates of OSA were reported by other studies, ranging from 14 to $45 \%[15,18,23,24]$. Association between OSA and thinning of calvarium and skull base has been reported [21], though the mechanism is still not precisely known. It is postulated that transient hypercarbia during the apneic episodes in patients with OSA syndrome results in cerebral vasodilation and transient elevations in ICP $[25,26]$, which may on the long run lead to gradual progressive thinning of bony skull base [27]. Detection of OSA 


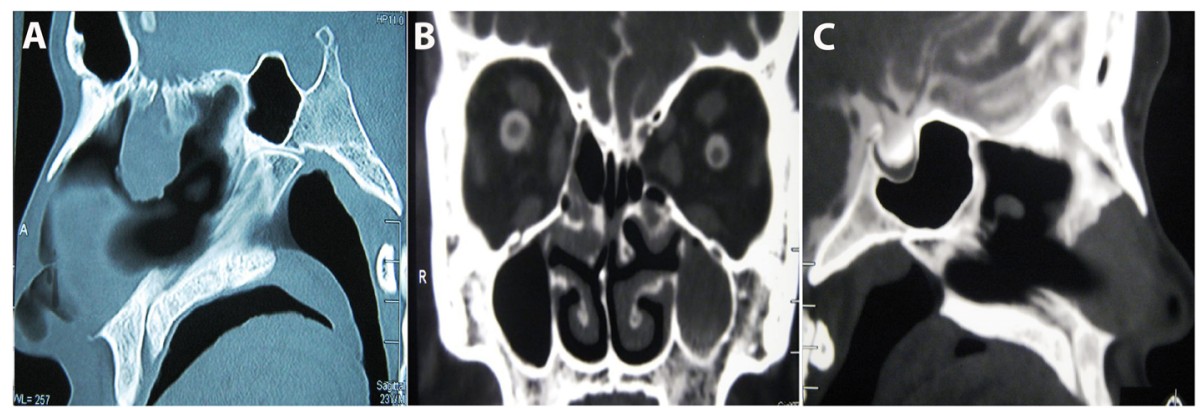

Fig. 2 CT scan sagittal section showing a skull base defect with meningocele protruding through it (a) and computerized tomography cisternogram showing peri-optic nerve cerebrospinal fluid congestion (b) and an empty sella (c)

Table 2 Clinical manifestations and radiological findings

\begin{tabular}{|c|c|}
\hline Parameter & Total number $=18$ \\
\hline Headache & $18(100.0 \%)$ \\
\hline Visual symptoms & $18(100.0 \%)$ \\
\hline \multicolumn{2}{|l|}{ Past history of meningitis } \\
\hline No & $16(88.9 \%)$ \\
\hline Yes & $2(11.1 \%)$ \\
\hline \multicolumn{2}{|l|}{ Sites of leakage } \\
\hline Cribriform/Ethmoidal & $3(16.7 \%)$ \\
\hline Cribriform & $12(66.7 \%)$ \\
\hline Ethmoidal & $1(5.6 \%)$ \\
\hline Sphenoid & $2(11.1 \%)$ \\
\hline \multicolumn{2}{|l|}{ Defect size (mm) } \\
\hline Mean \pm SD & $5.1 \pm 1.1$ \\
\hline Range & $3.0-7.0$ \\
\hline \multicolumn{2}{|l|}{ Number of defects } \\
\hline Single & $12(66.7 \%)$ \\
\hline Multiple & $6(33.3 \%)$ \\
\hline \multicolumn{2}{|l|}{ Encephaloceles } \\
\hline No & $7(38.9 \%)$ \\
\hline Yes & $11(61.1 \%)$ \\
\hline \multicolumn{2}{|l|}{ Meningoceles } \\
\hline No & $6(33.3 \%)$ \\
\hline Yes & $12(66.7 \%)$ \\
\hline \multicolumn{2}{|l|}{ MRI findings } \\
\hline Empty sella partialis & $1(5.6 \%)$ \\
\hline Empty sella totalis & $12(66.7 \%)$ \\
\hline Slit ventricle & $5(27.8 \%)$ \\
\hline Peri-optic CSF congestion & $14(77.7 \%)$ \\
\hline \multicolumn{2}{|c|}{ Preoperative CSF pressure $\left(\mathrm{mm} \mathrm{H}_{2} \mathrm{O}\right)$} \\
\hline Mean \pm SD & $36.5 \pm 1.7$ \\
\hline Range & $35.0-40.0$ \\
\hline
\end{tabular}

SD standard deviation, CSF cerebrospinal fluid syndrome in patients with spontaneous CSF leaks is recommended using polysomnography [16].

In the present study, the majority of patients (89.9\%) presented with unilateral CSF rhinorrhea as well as headache and visual symptoms; previous history of meningitis was detected in only two patients (11.1\%). The incidence of meningitis was approximate to that reported by Chaaban and his colleagues [17] of 9\%. However, a systematic review [7] reported a higher incidence of meningitis (23\%). A wide range of incidence of meningitis was reported by other studies, from 6 [20] to 58\% [28]. The presence of bone defects predisposes patients to meningitis [15].

In the present study, the radiographic imaging including thin slices $(1 \mathrm{~mm}) \mathrm{CT}$ scans combined with MRI of the paranasal sinuses and skull base have been done for all patients to detect the site and size of the defects and the contents of downward herniated neural structures. This was in agreement with Schuknecht and his colleagues [29]. As they stated that combination of CT scan and MRI together with intraoperative endoscopic

Table 3 Operative repair, follow-up, and outcome

\begin{tabular}{ll}
\hline Parameter & Total number $=\mathbf{1 8}$ \\
\hline Previous repair & $16(88.9 \%)$ \\
Second time & $2(11.1 \%)$ \\
Third time & \\
Repair & $7(38.9 \%)$ \\
Fat & $2(11.1 \%)$ \\
Fat, fascia lata and nasoesptal flap & $9(50.0 \%)$ \\
Fat and mucoperichondrium & \\
Failure & $16(88.9 \%)$ \\
No & $2(11.1 \%)$ \\
Yes & \\
Follow-up (months) & $24.5(18.0-30.0)$ \\
Median (IQR) & $6.0-60.0$ \\
Range &
\end{tabular}

IQR interquartile range 
findings will detect accurate site and size of osteodural defects. Unlike them, we did not perform CT cisternography as a routine investigation because it is an invasive technique.

We found that the most common site of leakage was the cribriform plate of the ethmoid (66.7\%), followed by leakage from both cribriform and ethmoidal bone $(16.7 \%)$, then sphenoid (11.1\%), and only one case with leakage from ethmoidal bone fovea ethmoidalis (5.6\%). Leakage of CSF is expected to occur from skull base regions that are inherently thin and pneumatized, such as the cribriform plate and the tegmen [15]. Our results are in partial accordance with previous studies reporting the cribriform plate and sphenoid as the most common sites for leakage $[7,8,15]$.

Increased ICP can appear radiologically in MRI in the form of encephalocele, empty sella, and vertical tortuosity of dilated optic nerve sheaths. Thinning of skull base with multiple bone erosions can be detected by computed tomography scan $[2,5,6,17]$. We found that encephalocele and meningocele were recorded in $61.1 \%$ and $66.7 \%$ of our cases, respectively. The radiological findings in our patients showed empty sella totalis in $66.7 \%$, slit ventricle only in $27.8 \%$, empty sella partialis in $5.6 \%$, and CSF congestion around optic nerve sheath in $77.7 \%$. These findings are supported by numerous previous studies. Encephaloceles were reported in 50 to $100 \%$ of spontaneous CSF leaks [9, 30]. Empty sella was also highly prevalent and reported in 85 to $100 \%$ of patients $[17,31]$.

In the present study, the sites of leakage during endoscopic repair was depended mainly on the pre-operative CT and MRI finding combined with endoscopic exploration without the use of intrathecal injection of fluorescein dye. As US FDA (United States Food and Drug Administration) had received 136 case reports (19692003) with 13 patients died as a result of adverse drug reactions. Furthermore, seizures, headaches, pulmonary edema, and lower extremities numbness have been reported Javadi and his colleagues [32]. For this reason, we excluded this technique from our protocol of management of CSF rhinorrhea.

The normal pressure range of CSF is from 5 to $15 \mathrm{~cm}$ $\mathrm{H}_{2} \mathrm{O}$, as detected on opening measurement via lumbar puncture [11]. All patients in our series had elevated CSF pressure. Their preoperative CSF pressure ranged from 35 to $40 \mathrm{~mm} \mathrm{H}_{2} \mathrm{O}$ (average of $36.5 \pm 1.7 \mathrm{~mm}$ $\mathrm{H}_{2} \mathrm{O}$ ). Elevated ICP over a period of years is suggested to cause bone thinning in the skull base that end in the formation of bone defects, through which "spontaneous" CSF leaks occur $[4,14,21]$.

Elevated CSF pressure was reported in 10-66\% of patients with spontaneous CSF leaks [33]. A recent systematic review by Teachey and his colleagues [34] reviewed
56 articles and concluded that $43.5 \%$ of patients in the included studies had signs of CSF hypertension on radiological imaging or through lumbar tap. However, the true prevalence of CSF hypertension in patients with spontaneous leaks cannot be estimated precisely, as many studies did not measure CSF pressure in those patients. The reported mean preoperative opening pressure of CSF in patients with anterior skull base defects was $33 \mathrm{~cm} \mathrm{H}_{2} \mathrm{O}$ [35]. Management of intracranial hypertension seems mandatory, as ICP has been shown to increase significantly after repair of skull base defects [11]. Although temporary use of lumbar drainage will decrease this pressure, ICP will remain elevated if no intervention is performed, subjecting the patient to both early and late failures.

Control of elevated ICP may be achieved by various methods, treatments with acetazolamide, permanent CSF diversion via a ventriculo-peritoneal shunt, decreased body weight by diet or bariatric surgery, or serial lumbar punctures [11, 36-38].

Lumbo-peritoneal shunting is an effective, safe procedure that has been used to treat IIH. The efficacy of this kind of shunting is maintained as long as the shunt remains patent [12]. Therefore, all patients in our series underwent lumbo-peritoneal shunt insertion.

In the current study, patients were followed-up after repair for a period ranging from 6 to 60 months, with a median follow-up period of 24.5 months (Table 3). Follow-up of the studied patients showed that the repair failed in only two cases (11.1\%). The reported success rates in previous studies vary widely, ranging from 33 to $100 \%[17,36,39]$. Higher success rates have been associated with management of increased ICP, such as ventriculo-peritoneal shunting, acetazolamide, and weight loss $[4,11,34,36]$. However, there is still some debate considering management of elevated ICP in patients with spontaneous CSF leaks [15]. The main concerns that may hinder the inclusion of ICP management techniques into routine care are adverse effects associated with these treatments, in addition to lack of evidence of their efficacy. Acetazolamide is a carbonic anhydrase inhibitor that may cause electrolyte and metabolic disturbances. Permanent CSF diversion by ventriculo-peritoneal shunt is an invasive cranial procedure that carries the risk of surgical site infections, meningitis and blockage, and migration of distal catheter. Moreover, overshunting leading to low pressure headaches and chronic subdural collections and hence shunt failure $[15,40]$. Lower complication and revision rate of $11 \%$ has been reported in the study of Bjornson and his colleagues [40] on 28 patients. Image guidance with electromagnetic (EM) navigation was mandatory for ventricular catheter insertion for their patients, whereas in 2014, Menger and his colleagues [41] published a retrospective cohort study, in which 4480 patients was diagnosed as idiopathic 
intracranial hypertension, with 2505 undergoing first-time VP shunt insertion and 1754 undergoing initial LP shunt, ventriculo-peritoneal shunts proven to be superior to lumbo-peritoneal shunts secondary to $\mathrm{IIH}$ regarding rate of revision surgery and average hospital stay period.

In current study, unfortunately image guidance (neuro-navigation) was not available in our institution for shunting of small sized ventricles.

Our study is in a partial accordance with the study of Woodworth and his colleagues [8]; as they managed 56 patients presented with initial spontaneous CSF rhinorrhea combined with increased intracranial tension through a 10-year study. They stated that the treatment of the underlying intracranial hypertension coupled with endoscopic repair in cases of spontaneous CSF leak carried a high success rate of (95\%) reaching that of other etiologies of CSF leaks. Intracranial pressures averaged 27 $\mathrm{cm} \mathrm{H}_{2} \mathrm{O}$. Patients were treated with acetazolamide. Meanwhile, in severe cases, with a ventriculo-peritoneal shunt, unlike our patients, all of them had recurrent CSF rhinorrhea with previous attempts to repair it whereas permanent CSF lumboperitoneal diversions were adopted for all of them.

In contrast to our study, Ahmed and his colleagues [42] proposed that the transvers venous sinus stenting (VSS) is a procedure with a favorable outcomes and lower complication rates. Their cost analysis showed that over 100 procedures performed, VSS weigh less than CSF shunting in the long term, not due to the average cost of the procedure itself but a relatively lower revision rate, fewer total revisions per patient, and less infections. This technique is not well established or familiar in our institute. Furthermore, in our study, the lumbo-peritoneal shunts were not coasty and of lower revision rate (11.1\%) as well.

Our data was partially in accordance with Locatelli and his colleagues [43], as they managed 135 patients over 9 years, $91 \%$ of them was purely endoscopic repair but all of them had normal intracranial tension with success rate 93.3\% [43]. Unlike our data, all patients were presented with a considerable increased ICP (35 to 40 $\mathrm{mm} \mathrm{H}_{2} \mathrm{O}$ ) and underwent purely endoscopic repair with success rate $89.9 \%$.

Our technique for repairing and reconstructions of the defects was as follows: small circular defects up to $5 \mathrm{~mm}$ were plugged with a single piece of fat and may be overlayed with mucoperichondrial. Defects more than $5 \mathrm{~mm}$ combined application of underlay fascia lata graft between brain and dura matter with fat plugs through osseous defect was done and then stabilized with layers of Surgicel and absorbable Gelatin.

There are various techniques for endoscopic skull base reconstruction, for example, Hadad and his colleagues [44] applied either vascularized flaps or non-vascularized grafts: vascularized flaps carried a high success rate like pedicled naso-septal flap which had been described for reconstruction of defects of the anterior, middle, clival, and parasellar skull base, while non-vascularized grafts like fat plugs and mucoperichondrial grafts were considered in skull base defects reconstruction [44]. In our study, we applied both techniques for reconstruction either vascularized naso-septal flaps or non-vascularized grafts.

Another study of Kassam and his colleagues [45] stated that the applied pressure for example the balloon of foly's catheter $12 \mathrm{~mm}$ reduce the risk of migration of the underlying grafts. Collagen matrix can be used as inlay graft between brain and dura matter. Fibrin sealants are no longer used between the inlay and onlay grafts. However, the application of lumbar drains no longer routinely used by Kassam et al. because it potentially creates negative pressure with the hazards of separation of the initial subdural inlay graft from the dural edges according to their experience [45]. We believe that lumbar drains might be accepted in primary cases of CSF leaks; in our study, we did not consider it as we had synchronously inserted lumbo-peritoneal shunt at the same sitting.

Another technique described by Cavallo and his colleagues [46] 3F (fat, flap, and flash) technique used with high success rate $96 \%$. After extended endoscopic endonasal approaches for achieving watertight skull base reconstruction, the 3F strategy involves autologous fat grafting, naso-septal flap coverage, and flash mobilization out of the bed following the operation. This technique can be used in reconstruction of various skull base defects. We recommend this technique for further upcoming research work.

The repair of skull base defects is achieved either via endoscopic or open craniotomy, whereas open repairs are through a bifrontal craniotomy approach which provides a direct access to the dural defect, the option to directly deal with nearby tissue injury, and the ability to apply a vascularized pericranial flap for grafting the anterior skull base. However, the hazards of brain retraction, anosmia, and morbidity associated with craniotomy are the main disadvantages of this approach [47]. For these reasons, we adopted the repair of the defects purely via endonasal endoscopic.

The limitations of the current study attributed mainly to relative rarity of recurrent spontaneous CSF rhinorrhea, rendering it with insufficient cohort sizes to perform a statistical analysis. However, operative techniques and perioperative protocols were the mainstay determinants of outcome.

\section{Conclusion}

Spontaneous CSF leaks are more prevalent in obese, female patients who suffer from OSA syndrome and 
increased ICP. Treatment success rate is higher in patients with spontaneous CSF leaks and CSF hypertension treated by Lumbo-peritoneal shunts. Future prospective studies with larger sample sizes should confirm the efficacy and safety of this management plan.

\section{Abbreviations}

CSF: Cerebrospinal fluid; BMI: Body mass index; ICP: Intracranial Pressure; OSA: Obstructive Sleep Apnea; IIH: Idiopathic Intracranial Hypertension

\section{Acknowledgement}

We would like to thank the medical statistical unit and, Tanta University Hospitals, for their great help in data interpretations.

\section{Authors' contributions}

AS: participated in the study's idea, design, patients' selection, data interpretation, data collection, statistical analysis, references collection, manuscript writing, revision, and final approval. KE: participated in the study's idea, design, patients' selection, data interpretation, data collection, references collection, manuscript writing, revision, and final approval. AF: participated in the study design, patients' assessment and inclusion, imaging interpretation, reference collection and manuscript writing, and final approval. All the authors have read and approved the final manuscript, and we believe the manuscript represents a valid work. Each author confirms they meet the criteria for authorship.

\section{Funding}

No funding had been received.

\section{Availability of data and materials}

The datasets used and/or analyzed during the current study are available from the corresponding author on reasonable request.

\section{Declarations}

\section{Consent of publication}

Not applicable.

\section{Ethics approval and consent to participate}

The manuscript was approved by the Research Ethics Committee and Quality Assurance Unit, Faculty of Medicine, Tanta University.

- The URL: http://tqac.tanta.edu.eg/new-tqac/ QualityAssuranceUnit@hotmail.com

- Approval Code: 33925/6/20

- Name of the PI: Ahmed Youssef Soliman.

- Name of the department: Neurosurgery.

- Type of the research: promotion research.

- Date of approval: June 2020.

- The study's protocol was approved by the Research Ethics Committee and Quality Assurance Unit, Faculty of Medicine, Tanta University. Participations were voluntary, informed written consents were approved by all participants' guardians, and any possible risks were clarified.

\section{Competing interests}

All authors disclose that they have no competing interests related to the study.

\section{Author details}

${ }^{1}$ Faculty of Medicine, Tanta University, Tanta 31527, Egypt. ${ }^{2}$ Faculty of Medicine, Tanta University, Tanta 31527, Egypt. ${ }^{3}$ Faculty of Medicine, Port Said University, Tanta 42511, Egypt.

Received: 22 September 2020 Accepted: 17 March 2021

Published online: 31 March 2021

\section{References}

1. Zweig JL, Carrau RL, Celin SE, Schaitkin BM, Pollice PA, Snyderman CH, et al. Endoscopic repair of cerebrospinal fluid leaks to the sinonasal tract: predictors of success. Otolaryngol Head Neck Surg. 2000;123(3):195-201. https://doi.org/10.1067/mhn.2000.107452.
2. Banks CA, Palmer JN, Chiu AG, O'Malley BW Jr, Woodworth BA, Kennedy DW. Endoscopic closure of CSF rhinorrhea: 193 cases over 21 years. Otolaryngol Head Neck Surg. 2009;140(6):826-33. https://doi.org/10.1016/j. otohns.2008.12.060.

3. Schlosser RJ, Wilensky EM, Grady MS, Bolger WE. Elevated intracranial pressures in spontaneous cerebrospinal fluid leaks. Am J Rhinol. 2003;17(4): 191-5. https://doi.org/10.1177/194589240301700403.

4. Schlosser RJ, Woodworth BA, Wilensky EM, Grady MS, Bolger WE. Spontaneous cerebrospinal fluid leaks: a variant of benign intracranial hypertension. Ann Otol Rhinol Laryngol. 2006;115(7):495-500. https://doi. org/10.1177/000348940611500703.

5. Aaron G, Doyle J, Vaphiades MS, Riley KO, Woodworth BA. Increased intracranial pressure in spontaneous CSF leak patients is not associated with papilledema. Otolaryngol Head Neck Surg. 2014;151(6):1061-6. https://doi. org/10.1177/0194599814551122.

6. Aaron GP, Illing E, Lambertsen Z, Ritter M, Middlebrooks EH, Cure J, et al. Enlargement of Meckel's cave in patients with spontaneous cerebrospinal fluid leaks. Int Forum Allergy Rhinol. 2017;7(4):421-4. https://doi.org/10.1 002/alr.21891.

7. Psaltis AJ, Schlosser RJ, Banks CA, Yawn J, Soler ZM. A systematic review of the endoscopic repair of cerebrospinal fluid leaks. Otolaryngol Head Neck Surg. 2012;147(2):196-203. https://doi.org/10.1177/0194599812451090.

8. Woodworth BA, Prince A, Chiu AG, Cohen NA, Schlosser RJ, Bolger WE, et al. Spontaneous CSF leaks: a paradigm for definitive repair and management of intracranial hypertension. Otolaryngol Head Neck Surg. 2008;138(6):71520. https://doi.org/10.1016/j.otohns.2008.02.010.

9. Schlosser RJ, Bolger WE. Nasal cerebrospinal fluid leaks: critical review and surgical considerations. Laryngoscope. 2004;114(2):255-65. https://doi.org/1 0.1097/00005537-200402000-00015

10. Alexander NS, Chaaban MR, Riley KO, Woodworth BA. Treatment strategies for lateral sphenoid sinus recess cerebrospinal fluid leaks. Arch Otolaryngol Head Neck Surg. 2012;138(5):471-8.

11. Chaaban MR, Illing E, Riley KO, Woodworth BA. Acetazolamide for high intracranial pressure cerebrospinal fluid leaks. Int Forum Allergy Rhinol. 2013;3(9):718-21. https://doi.org/10.1002/alr.21188.

12. Binder DK, Horton JC, Lawton MT, McDermott MW. Idiopathic intracranial hypertension. Neurosurgery. 2004;54(3):538-52. https://doi.org/10.1227/01. NEU.0000109042.87246.3C

13. Badve M, McConnell M, Shah T, Ondecko-Ligda K, Poutous G, Vallejo MC. Idiopathic intracranial hypertension in pregnancy treated with serial lumbar punctures. Int J Clin Med. 2011;2(01):9-12. https://doi.org/10.4236/ijcm.2 011.21003 .

14. Nelson RF, Hansen KR, Gantz BJ, Hansen MR. Calvarium thinning in patients with spontaneous cerebrospinal fluid leak. Otol Neurotol. 2015:36(3):481-5. https://doi.org/10.1097/MAO.0000000000000552.

15. Lobo BC, Baumanis MM, Nelson RF. Surgical repair of spontaneous cerebrospinal fluid (CSF) leaks: a systematic review. Laryngoscope Investig Otolaryngol. 2017;2(5):215-24. https://doi.org/10.1002/lio2.75.

16. Nelson RF, Roche JP, Gantz BJ, Hansen MR. Middle cranial fossa (MCF) approach without the use of lumbar drain for the management of spontaneous cerebral spinal fluid (CSF) leaks. Otol Neurotol. 2016;37(10): 1625-9. https://doi.org/10.1097/MAO.0000000000001208.

17. Chaaban MR, Illing E, Riley KO, Woodworth BA. Spontaneous cerebrospinal fluid leak repair: a five-year prospective evaluation. Laryngoscope. 2014; 124(1):70-5. https://doi.org/10.1002/lary.24160.

18. Nelson RF, Gantz BJ, Hansen MR. The rising incidence of spontaneous cerebrospinal fluid leaks in the United States and the association with obesity and obstructive sleep apnea. Otol Neurotol. 2015;36(3):476-80. https://doi.org/10.1097/MAO.0000000000000535.

19. Quatre R, Attye A, Righini CA, Reyt E, Giai J, Schmerber S, et al. Spontaneous cerebrospinal fluid rhinorrhea: association with body weight and imaging data. J Neurol Surg B Skull Base. 2017;78(5):419-24. https://doi.org/10.1055/ s-0037-1603731.

20. Son HJ, Karkas A, Buchanan P, Giurintano JP, Theodosopoulos P, Pensak ML, et al. Spontaneous cerebrospinal fluid effusion of the temporal bone: repair, audiological outcomes, and obesity. Laryngoscope. 2014;124(5):1204-8. https://doi.org/10.1002/lary.24484.

21. Rabbani C, Saltagi MZ, Ye MJ, Patel JM, Manchanda S, Nelson RF. Association of obstructive sleep apnea with calvarial and skull base thinning. JAMA Otolaryngol Head Neck Surg. 2018;144(6):513-8. https://doi. org/10.1001/jamaoto.2018.0347 
22. Rabbani CC, Saltagi MZ, Manchanda SK, Yates CW, Nelson RF. Prevalence of obstructive sleep apnea (OSA) in spontaneous cerebrospinal fluid (CSF) leaks: a prospective cohort study. Otol Neurotol. 2018;39(6):e475-e80. https://doi.org/10.1097/MAO.0000000000001805.

23. Fleischman GM, Ambrose EC, Rawal RB, Huang BY, Ebert CS Jr, Rodriguez $\mathrm{KD}$, et al. Obstructive sleep apnea in patients undergoing endoscopic surgical repair of cerebrospinal fluid rhinorrhea. Laryngoscope. 2014;124(11): 2645-50. https://doi.org/10.1002/lary.24661.

24. Thurtell MJ, Trotti LM, Bixler EO, Rye DB, Bliwise DL, Newman NJ, et al. Obstructive sleep apnea in idiopathic intracranial hypertension: comparison with matched population data. J Neurol. 2013;260(7):1748-51. https://doi. org/10.1007/s00415-013-6858-6.

25. Jennum P, Børgesen SE. Intracranial pressure and obstructive sleep apnea. Chest. 1989;95(2):279-83. https://doi.org/10.1378/chest.95.2.279.

26. Sugita Y, lijima S, Teshima Y, Shimizu T, Nishimura N, Tsutsumi T, et al. Marked episodic elevation of cerebrospinal fluid pressure during nocturnal sleep in patients with sleep apnea hypersomnia syndrome. Electroencephalogr Clin Neurophysiol. 1985;60(3):214-9. https://doi.org/10.1 016/0013-4694(85)90033-1.

27. Rabbani CC, Saltagi MZ, Nelson RF. The role of obesity, sleep apnea, and elevated intracranial pressure in spontaneous cerebrospinal fluid leaks. Curr Opin Otolaryngol Head Neck Surg. 2019;27(5):349-55. https://doi.org/10.1 097/MO0.0000000000000562.

28. Markou K, Goudakos J, Franco-Vidal V, Vergnolles V, Vignes J-R, Darrouzet V. Spontaneous osteodural defects of the temporal bone: diagnosis and management of 12 cases. Am J Otolaryngol. 2011;32(2):135-40. https://doi. org/10.1016/j.amjoto.2009.12.003

29. Schuknecht B, Simmen D, Briner HR, Holzmann D. Nontraumatic skull base defects with spontaneous CSF rhinorrhea and arachnoid herniation: imaging findings and correlation with endoscopic sinus surgery in 27 patients. AJNR Am J Neuroradiol. 2008;29(3):542-9. https://doi.org/10.3174/a jnr.A0840.

30. Schick B, Ibing R, Brors D, Draf W. Long-term study of endonasal duraplasty and review of the literature. Ann Otol Rhinol Laryngol. 2001;110(2):142-7. https://doi.org/10.1177/000348940111000209.

31. Schlosser RJ, Bolger WE. Significance of empty sella in cerebrospinal fluid leaks. Otolaryngol Head Neck Surg. 2003;128(1):32-8. https://doi.org/10.1 067/mhn.2003.43

32. Javadi SA, Samimi H, Naderi F, Shirani M. The use of low- dose intrathecal fluorescein in endoscopic repair of cerebrospinal fluid rhinorrhea. Arch Iran Med. 2013;16(5):264-266, DOI: 013165/AIM.004.

33. Brainard L, Chen DA, Aziz KM, Hillman TA. Association of benign intracranial hypertension and spontaneous encephalocele with cerebrospinal fluid leak. Otol Neurotol. 2012;33(9):1621-4. https://doi.org/10.1097/MAO.0b013e3182 71c312.

34. Teachey W, Grayson J, Cho D-Y, Riley KO, Woodworth BA. Intervention for elevated intracranial pressure improves success rate after repair of spontaneous cerebrospinal fluid leaks. Laryngoscope. 2017;127(9):2011-6. https://doi.org/10.1002/lary.26612.

35. Martínez-Capoccioni G, Serramito-García R, Martín-Bailón M, García-Allut A, Martín-Martín C. Spontaneous cerebrospinal fluid leaks in the anterior skull base secondary to idiopathic intracranial hypertension. Eur Arch Otorhinolaryngol. 2017;274(5):2175-81. https://doi.org/10.1007/s00405-01 7-4455-5.

36. Chiu AG, Palmer JN, Woodworth BA, Doghramji L, Cohen MB, Prince A, et al. Baby shampoo nasal irrigations for the symptomatic post-functional endoscopic sinus surgery patient. Am J Rhinol. 2008;22(1):34-7. https://doi. org/10.2500/ajr.2008.22.3122.

37. Virk JS, Elmiyeh B, Saleh HA. Endoscopic management of cerebrospinal fluid rhinorrhea: the charing cross experience. J Neurol Surg B Skull Base. 2013; 74(2):61-7. https://doi.org/10.1055/s-0033-1333620.

38. Stangherlin $\mathrm{P}$, Ledeghen $\mathrm{S}$, Scordidis $\mathrm{V}$, Rubay R. Benign intracranial hypertension with recurrent spontaneous cerebrospinal fluid rhinorrhoea treated by laparoscopic gastric banding. Acta Chir Belg. 2008;108(5):616-8. https://doi.org/10.1080/00015458.2008.11680302.

39. Illing E, Schlosser RJ, Palmer JN, Curé J, Fox N, Woodworth BA. Spontaneous sphenoid lateral recess cerebrospinal fluid leaks arise from intracranial hypertension, not Sternberg's canal. Int Forum Allergy Rhinol. 2014;4(3):24650. https://doi.org/10.1002/alr.21262.

40. Bjornson A, Tapply I, Nabbanja E, Lalou AD, Czosnyka M, Czosnyka Z, et al. Ventriculo-peritoneal shunting is a safe and effective treatment for idiopathic intracranial hypertension. Br J Neurosurg. 2019;33(1):62-70. https://doi.org/10.1080/02688697.2018.1538478.

41. Menger RP, Connor DE Jr, Thakur JD, Sonig A, Smith E, Guthikonda B, et al. A comparison of lumboperitoneal and ventriculoperitoneal shunting for idiopathic intracranial hypertension: an analysis of economic impact and complications using the Nationwide Inpatient Sample. Neurosurg Focus. 2014;37(5):E4. https://doi.org/10.3171/2014.8.FOCUS14436.

42. Ahmed RM, Zmudzki F, Parker GD, Owler BK, Halmagyi GM. Transverse sinus stenting for pseudotumor cerebri: a cost comparison with CSF shunting. AJNR Am J Neuroradiol. 2014;35(5):952-8. https://doi.org/10.3174/ajnr.A3806.

43. Locatelli D, Rampa F, Acchiardi I, Bignami M, De Bernardi F, Castelnuovo P. Endoscopic endonasal approaches for repair of cerebrospinal fluid leaks: nine-year experience. Neurosurgery. 2006;58(4 Suppl 2) ONS-246-56; discussiom ONS-256-47.

44. Hadad G, Bassagasteguy L, Carrau RL, Mataza JC, Kassam A, Snyderman CH, et al. A novel reconstructive technique after endoscopic expanded endonasal approaches: vascular pedicle nasoseptal flap. Laryngoscope. 2006; 116(10):1882-6. https://doi.org/10.1097/01.mlg.0000234933.37779.e4.

45. Kassam A, Carrau RL, Snyderman CH, Gardner P, Mintz A. Evolution of reconstructive techniques following endoscopic expanded endonasal approaches. Neurosurg Focus. 2005;19(1):E8.

46. Cavallo LM, Solari D, Somma T, Cappabianca P. The 3F (fat, flap, and flash) Technique for skull base reconstruction after endoscopic endonasal suprasellar approach. World Neurosurg. 2019;126:439-46. https://doi.org/1 0.1016/j.wneu.2019.03.125.

47. Snyderman CH, Janecka IP, Sekhar LN, Sen CN, Eibling DE. Anterior cranial base reconstruction: role of galeal and pericranial flaps. Laryngoscope. 1990; 100(6):607-14. https://doi.org/10.1288/00005537-199006000-00011.

\section{Publisher's Note}

Springer Nature remains neutral with regard to jurisdictional claims in published maps and institutional affiliations.

\section{Submit your manuscript to a SpringerOpen ${ }^{\circ}$ journal and benefit from:}

- Convenient online submission

- Rigorous peer review

- Open access: articles freely available online

High visibility within the field

- Retaining the copyright to your article

Submit your next manuscript at $\boldsymbol{\nabla}$ springeropen.com 